\title{
АГРОТЕХНОЛОГИЯ ВЫРАЩИВАНИЯ МНОГОЛЕТНИХ ТРАВ В ГАЗОННОЙ КУЛЬТУРЕ ЮГА КРАСНОЯРСКОГО КРАЯ
}

\section{N. Tisova, V. N. Romanov, G. A. Demidenko}

\section{THE AGROTECHNOLOGY OF GROWING PERENNIAL HERBS IN LAWN CULTURE OF THE SOUTH OF KRASNOYARSK REGION}

Тисова Лариса Николаевна - гл. агроном ООО «Сады Семирамиды», г. Красноярск.

E-mail: sad.academ@mail.ru

Романов Василий Николаевич - д-р с.-х. наук, вед. науч. сотр. отдела агротехнологий Красноярского НИИ сельского хозяйства - обособленного подразделения ФИЦ КНЦ СО РАН, г. Красноярск. E-mail: romanov1948@yandex.ru

Демиденко Галина Александровна - д-р биол. наук, проф., зав. каф. ландшафтной архитектуры, ботаники, агроэкологии Красноярского государственного аграрного университета, г. Красноярск.

E-mail: demidenkoekos@mail.ru

Цель исследования - совершенствование технологии выращивания многолетних мятликовых трав в условиях газонной культуры юга Красноярского края. Решались задачи по обоснованию набора трав для создания современных типов газонов, совершенствованию агротехнологии выращивания многолетних трав в газонной культуре, выбору типов газонов, их функциональной значимости для использования в рекреационных зонах города. Объектами изучения являлись травянистые растения, воздельваемые по современным агротехнологиям в газонной культуре. Использовались общепринятые методики создания и ухода за газонным покрытием: ГОСТ 28329-89; ГОСТ 17.8.01-86; ГОСТ 17.5.1.01-83 u др. Работы выполнены на базе 000 «Сады Семирамиды» в 2001-2019 г2. Современная агротехнология выращивания многолетних мятликовых трав в газонной культуре юга Красноярского края включает создание плодородного слоя, тщательную обработку почвы, качественный посев травосмесей и уход за посевами. Выбор определенных типов газонов зависит от природных условий территории,
Tisova Larisa Nikolaevna - Chief Agronomist, JSC 'Sady Semiramidy', Krasnoyarsk. E-mail: sad.academ@mail.ru Romanov Vasily Nikolaevich - Dr. Agr. Sci., Leading Staff Scientist, Department of Agrotechnologies, Krasnoyarsk Research Institute of Agriculture - Separate Division FRC KRC SB RAS, Krasnoyarsk.

E-mail: romanov1948@yandex.ru

Demidenko Galina Alexandrovna - Dr. Biol. Sci., Prof., Head, Chair of Landscape Architecture, Botany, Agroecology, Krasnoyarsk State Agrarian University, Krasnoyarsk.

E-mail: demidenkoekos@mail.ru

их фуннкциональной значимости. Для использования в рекреационных зонах города Красноярска и его пригородов наиболее приемлемы газоны «обыкновенный» и «луговой». Для декоративности и усиления функции украшения ландшаффтно-архитектурных ансамблей «партерный» газон. Подбор травосмесей газонных трав для создания газонов включает травы: мятлик луговой, райграс пастбищный, овсяница луговая, овсяница красная, овсяница овечья, полевица побегоносная. Смешивание этих трав в нужной пропорции позволяет создавать качественные, долголетние газоны. Практическая составляющая исследования заключается в необходимости организации совместно с Министерством сельского хозяйства и торговли края производства семян многолетних мятликовых трав.

Ключевые слова: многолетние травы, агротехнология выращивания, газоны, качество газонов, удобрения, полив, скашивание.

The research objective was the improvement of the technology of cultivation of perennial mint herbs under the conditions of lawn culture of Krasnoyarsk 
Region. The problems of justification of the set of herbs for the creation of modern types of lawns, to the improvement of the agrotechnology of cultivation of perennial herbs in lawn culture, to the choice of types of lawns, their functional importance for using in recreational zones of the city were solved. The objects of the study were grassy plants cultivated according to modern agrotechnologies in lawn culture. The standard techniques of creation and care of lawn covering were used: State Standard 2832989; State Standard 17.8.01-86; State Standard 17.5.1.01-83, etc. The researches were performed on the basis of JSC 'Sady Semiramidy' in 20012019. Modern agrotechnology of cultivation of perennial mint herbs in lawn culture of the South of Krasnoyarsk Region included the creation of fertile layer, careful processing of the soil, high-quality grass mix crops and crops care. The choice of certain types of lawns depended on the environment of the territory, their functional importance. For using in recreational zones of Krasnoyarsk and its suburbs the lawns "ordinary" and "meadow" were most acceptable. For decorative effect and strengthening the function of decoration of landscape architectural complexes "parter" lawn was used. The selection of grass mix for lawn herbs for the creation of lawns included the herbs: meadow mint, grazing range, meadow oatmeal, red oatmeal, sheep oatmeal, bovine. Mixing these herbs in the necessary proportion allows creating qualitative lawns with large terms of office. Practical component of the researches is in the need for the organization of the production of seeds of perennial mint herbs under the supervision of the Ministry of Agriculture and Trade of the Region.

Keywords: perennial herbs, growing agrotechnology, lawns, lawn quality, fertilizers, watering, skewing.

Введение. Многолетние травы являются ценными сельскохозяйственными культурами. Используя в агроценозах с разными целями, их включают в основную ротацию севооборота, выращивают на корм сельскохозяйственным животным, используют для рекреации при создании благоприятной окружающей среды и т. д.

Для получения 7 тыс. кг молока от коровы в год и среднесуточного прироста живой массы молодняка КРС на уровне 750 г в структуре посевов кормовых культур многолетние травы должны занимать 34 \%, а суммарная площадь выращивания кормовых культур должна составлять 2,3 га на 1 гол. [1-3]. Следовательно, многолетние травы являются важнейшей составляющей корма для животных.

Другой, не менее важной функцией многолетних трав является защита почвы от эрозии. Удерживая мелкозем на поверхности почвы, травы снижают экологическую напряженность, особенно в степных и лесостепных районах. Большинство городов и сел Красноярского края подвержены экологическому напряжению в течение всего календарного года. Весной и летом усиленный ветровой режим вызывает пыльные бури, экологическая нагрузка усиливается за счет выбросов промышленных предприятий, выхлопных газов и пыли, получаемой при движении транспортных средств. В зимнее время к этим загрязнителям добавляется дым от отопительных печей частного сектора и дачных массивов, прилегающих к городским территориям. Снижение влияния антропогенного и техногенного воздействий на городскую среду является актуальной задачей.

Одним из наиболее доступных и реальных путей снижения экологического напряжения в атмосфере является создание рекреационных зон, расширение площадей скверов и газонов [4-6].

Путем выращивания различных трав, преимущественно многолетних видов семейства мятликовых, создается газон [7, 8]. В жаркие дни температура воздуха на газоне (на высоте роста человека) на 6-7 ${ }^{\circ} \mathrm{C}$ ниже, чем на ассральтовом покрытии. С каждого квадратного метра подстриженной травы газона испаряется до 200 мл воды в час, что повышает влажность и улучшает микроклимат территории. Каждый квадратный метр газона связывает до 6 кг пыли и в значительной мере снижает уровень шума $[9,10]$.

Цель исследования: использование 15летнего опыта ООО «Сады Семирамиды» для создания газонов и совершенствование методики использования агротехнологии выращивания многолетних мятликовых трав в условиях газонной культуры юга Красноярского края.

\section{Задачи исследования:}

1. Методический подход создания газона с учетом 15-летнего опыта практической работы ООО «Сады Семирамиды». 
2. Обоснование набора трав для создания современных типов газонов, совершенствование технологии выращивания и ухода за газоном.

3. Выбор типов газонов по их функциональной значимости для использования в рекреационных зонах города.

4. Обоснование необходимости совместно с Министерством сельского хозяйства и торговли организации производства семян многолетних мятликовых трав в условиях юга Красноярского края.

Объекты и методы исследования. Объектами изучения являются многолетние травянистые растения, выращиваемые по современным агротехнологиям в газонной культуре города Красноярска и прилегающих территорий.

В настоящее время наиболее распространенными являются газоны «обыкновенные», состоящие из мятликовых трав, способных образовывать сплошную дернину; «луговые», в которых кроме мятликовых используются травянистые растения других семейств; «партерные», имеющие однородный, низкий, густой сомкнутый покров. В создании качественного и долголетнего газона используются смеси многолетних мятликовых трав [11]. Технология основана на тщательной подготовке почвы, оптимальном наборе видов трав в своевременном посеве и тщательном уходе за травяным покровом.

В исследовании используются общепринятые методики создания и ухода за газонным покрытием; ГОСТ 28329-89; ГОСТ 17.8.01-86; ГОСТ 17.5.1.01-83; рекомендации по выращиванию многолетних трав [12, 13]; методика определения качества газона (А.А. Лаптев (1983)). Исследование проводилось на базе 000 «Сады Семирамиды» в 2001-2019 гг.

Результаты исследования и их обсуждение. По итогам анализа методического подхода 15-летнего опыта деятельности ООО «Сады Семирамиды» по созданию газонов разного типа стало возможным выделение этапов агротехнолологии, характеризующихся определенными особенностями.

Создание густого и плотного травянистого покрова включает осеннюю (зяблевую) вспашку плугом с боронованием или перекопку почвы на глубину не менее 20 см с оборачиванием пласта на $180^{\circ}$ с последующей разделкой поверхностного слоя с помощью фррезы. Тщательная разделка является необходимой для лучшего накопления и сохранения влаги в почве и мобилизации доступных элементов питания растений (табл. 1).

Таблица 1

\section{Оптимальное содержание гумуса и питательных веществ в почве}

\begin{tabular}{|l|c|c|c|}
\hline \multicolumn{1}{|c|}{ Агрохимический показатель } & \multicolumn{3}{|c|}{ Тип газонов } \\
\cline { 2 - 4 } & Луговые & Обыкновенные & Партерные \\
\hline Гумус по Тюрину, \% & 2 & 3 & $4-4,5$ \\
\hline $\begin{array}{l}\text { Азот легко гидролизуемый по Тюрину, } \\
\text { мг/100 г почвы }\end{array}$ & 4 & 5 & 6 \\
\hline Фосфор по Кирсанову, мг/100 г почвы & 6 & 8 & $10-12$ \\
\hline Калий по Пейве, мг/100 г почвы & 6 & 7 & 10 \\
\hline
\end{tabular}

Поверхностный слой почвы должен иметь суглинистый или песчано-суглинистый гранулометрический состав, обладать нейтральной или слабокислой реакцией среды. Мощность плодородного слоя, в зависимости от характера нижележащего грунта и уровня залегания грунтовых вод, должна быть в пределах 20-50 см. На участках, где мощность плодородного слоя менее $10 \mathrm{~cm}$, добавляется плодородная почвосмесь, содержащая перегной и песок. На заболоченных или излишне увлажненных почвах необходимо создание дренажа.
Технология подготовки плодородного слоя включает: удаление верхнего слоя почвы; укладку ПЩС фракции 0-10 мм мощностью 2025 см, насыпку слоя песка 10-15 см и возвращение снятого ранее слоя 20-25 см плодородной почвосмеси, состоящей из $50 \%$ чернозема, $25 \%$ песка и $25 \%$ перегноя или торфа, которые хорошо перемешиваются (рис.).

Для нейтрализации повышенной кислотности добавляется известь. 


\section{Схема слоёв под устройство газона}

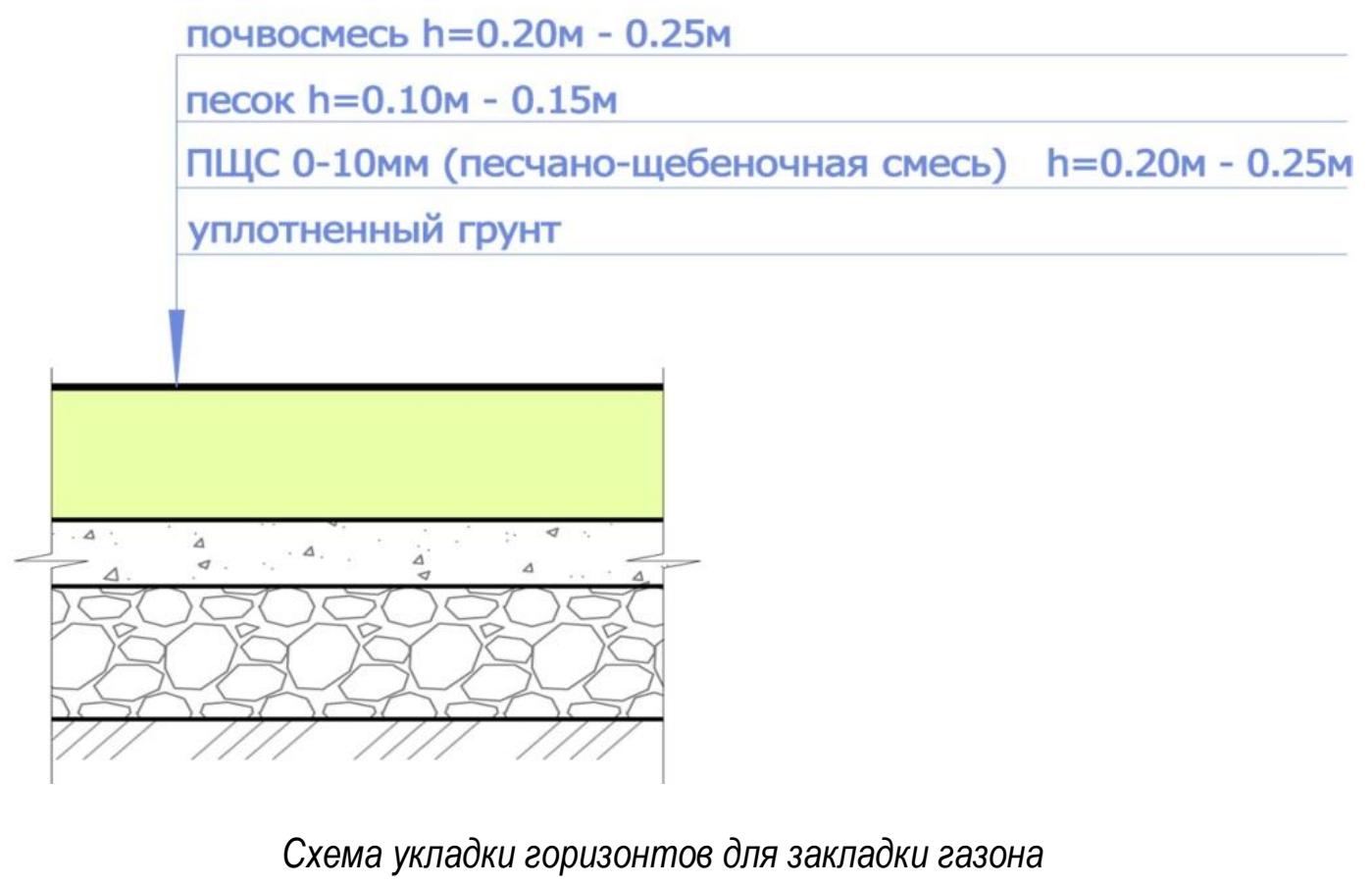

Выбор травосмеси. Оптимальная травосмесь включает 5-6 видов трав. Это повышает устойчивость газона к заболеваниям, засухе, морозам и другим экстремальным фракторам. В смесь специально добавляем сорта, обладающие сочной зеленью, медленным отрастанием, быстрым укоренением, что позволяет успешно бороться с сорняками.

Для создания газонов используем травы, допущенные Росреестром для возделывания в условиях Красноярского края: мятлик луговой, райграс пастбищный, овсяница луговая, овсяница красная, овсяница овечья, полевица побегоносная. Ботанические характеристики этих трав позволяют при смешивании их в нужной пропорции создавать качественные газоны.

Семена газонных трав мелкие (до 2-7 мм), поэтому следует учитывать, что газонные травы на первых этапах формирования развиваются медленно и подавляются сорными растениями. В среднем расчетная потребность семян должна обеспечивать 10 тыс. шт/M² побегов и составлять $40 \mathrm{r} / \mathrm{M}^{2}$. Расчет нормы высева семян травосмеси проводится по формуле

$$
X=\frac{H \cdot \Pi}{\text { Д}},
$$

где $\mathrm{H}$ - норма высева семян (при 100 \% хозяйственной годности) в чистом виде; П - процент участия вида в травосмеси, \% (табл. 2); Д фактическая хозяйственная годность, \%.

Агрессивные виды многолетних трав (к ним относятся райграс пастбищный тетраплоидный, райграс многоукосный), способные быстро осваивать территорию, вытесняя другие, как правило, более декоративные виды, высевают с меньшей нормой, в пределах $35 \mathrm{r} / \mathrm{M}^{2}$.

Посев газонных трав. Перед посевом трав почву прикатываем гладкими водоналивными или кольчатыми катками. Сеем в безветренную погоду, обеспечивая равномерное распределение семян на заданном участке. Норму высева для лучшей равномерности делим на две равные части и высеваем каждую в перпендикулярном направлении. Участки малой площади засеваем, разбрасывая семена вручную или с помощью гидропосева. 
Состав травосмесей в зависимости от природных условий

\begin{tabular}{|l|c|c|c|}
\hline \multirow{2}{*}{ Вид трав } & \multicolumn{3}{|c|}{ Содержание в смеси, \% } \\
\cline { 2 - 4 } & Засушливые участки & Песчаные почвы & Затененные участки \\
\hline Райграс пастбищный & 10 & 25 & 25 \\
\hline Овсяница красная & 35 & 20 & 50 \\
\hline Овсяница тростниковидная & 50 & 45 & 20 \\
\hline Мятлик луговой & 5 & 10 & 5 \\
\hline
\end{tabular}

После посева участок необходимо вновь прикатать для обеспечения плотного контакта семян с почвой и подтягивания влаги в верхний слой. Для защиты посевов от птиц и механических повреждений засеянный участок укрываем нетканым укрывным материалом плотностью 17 г/M². При необходимости участок осторожно поливаем по укрывному материалу, не допуская смыва семян.

Всходы, как правило, появляются через 7-10 дней, и при обнаружении проплешин сразу же подсеваем резервными семенами, которые высевали в первый срок. Лучшим сроком посева трав является весна, при температуре почвы в течение суток не менее $+5{ }^{\circ} \mathrm{C}$. При возможности полива участка посев газонов можно производить и в летний период (до 20 августа). Более поздний срок посева не гарантирует качественной перезимовки всходов трав.

Когда трава поднимается до 6 см, снимаем укрывной материал. При достижении травы 10 см высоты производим первое скашивание газона на высоту 8 см, второе скашивание проводим через 7 дней на высоту 6 см. Частые скашивания газонных растений, особенно первые 2 года их жизни, способствуют более активному побегообразованию, стимулируют разрастание корней, формирование прочной дернины.

Первое весеннее скашивание газонного травостоя следует производить с осторожностью, высотой не ниже 8-10 см, все последующие при достижении растениями высоты 10-12 см. Оптимальная высота скашивания травостоя не ниже 5-6 см. Более низкий срез быстрее ослабляет травостой. Скошенная трава используется в качестве зеленого удобрения (сидерат), для мульчирования поверхности почвы, подкормки и на подстилку животным в зоопарках.
При задержке очередного скашивания и перерастании травостоя происходит существенная перестройка, связанная с переходом растений к генеративному развитию. При скашивании переросших растений отторгается большая надземная масса побегов и листьев, а растениям для восстановления жизненной активности требуется длительное время.

Полив. Газоны нуждаются не только в благоприятных почвенных условиях, но и в обильном водоснабжении. В трудозатратах по уходу за газоном 80 \% составляют затраты на полив. В условиях Красноярска для газонных растений выявлены оптимальные условия увлажнения почвы, соответствующие 70-80 \% от полной почвенной влагоемкости, при этом пропитывается верхний слой на глубину 8-10 см. Такая влажность достигается равномерным поливом путем разбрызгивая 20-30 л воды на 1 м². Используемый автоматический полив превосходит ручной полив. По равномерности орошения, с соблюдением графика полива и объема воды, автоматический полив превосходит ручной.

Освежающие поливы чередуются с влагозарядковыми. При длительном переувлажнении отмечается ослабленное состояние побегов, которые приобретают нитевидную форму, и наблюдается процесс закисления почвы. Большое значение в поддержании хорошего состояния газона является водоотведение поверхностных вод за счет нужного уклона поверхности земельного участка (минимальный уклон составляет около 1 см падения высоты на 10 м длины в сторону сброса поверхностных вод), а также сооружение системы лотков с выходом за границы участка или дренажных колодцев для сбора излишков воды.

Однородность газонного травостоя. Присутствие в травостое сорных растений сни- 
жает декоративные качества и способствует непроизводительному выносу питательных веществ из почвы газона.

Ручная прополка газона трудоемкий, но необходимый прием в первый год вегетации растений. В последующем для борьбы с сорняками на газонах применяем гербициды избирательного действия.

Подкормки газона удобрениями. Частые скашивания газонов ослабляют растения, поэтому для обеспечения нормального питания и отрастания растений после скашивания требу- ется применение системы удобрений, что позволяет газонным травам активнее отрастать после очередного скашивания, интенсивно куститься, образуя сочный декоративный травостой. Для нормального роста и развития газонных растений необходимы: азот, фосфор, калий и микроэлементы (табл. 3). Потребность газонных трав в питательных веществах значительно эффрективнее обеспечивается при дробном внесении минеральных удобрений в виде подкормок с оптимальным соотношением основных элементов.

Нормы внесения минеральных удобрений, д.в. г/м²

\begin{tabular}{|l|c|c|c|}
\hline \multirow{2}{*}{ Срок внесения удобрений } & \multicolumn{3}{c|}{ Вид удобрений } \\
\cline { 2 - 4 } & $\mathrm{N}$ & $\mathrm{P}$ & $\mathrm{K}$ \\
\hline Первая весенняя подкормка, начало отрастания & 10 & 5 & 4 \\
\hline После первого скашивания & 5 & 2 & 2 \\
\hline Подкормка в июне & 5 & - & - \\
\hline Подкормка в июле & 5 & - & - \\
\hline Подкормка, 20 августа & 3 & - & - \\
\hline В сентябре & - & 2 & 4 \\
\hline Всего & 28 & 9 & 10 \\
\hline
\end{tabular}

По мере эксплуатации трав, на 3-й год вегетации наблюдается угнетение растений вследствие уплотнения дернового покрытия и роста корневой системы. Уплотнение дернины ведет к сокращению количества побегов, нарушается фотосинтез. Для устранения таких последствий проводим аэрацию, прокалывая дерн на глубину 7-10 см, и ежегодное прочесывание травостоя весной с помощью вертикутера. Весьма эфффективным приемом по уходу за газонным травостоем является землевание - поверхностное покрытие его перегноем, почвосмесью, состоящей из хорошо перепревших органических удобрений, песка и других компонентов (1 часть перегноя или компоста, 1 часть суглинистой почвы и 2 части крупного песка). Лучшие сроки проведения землевания - весна и осень. Норма расхода смеси - около $1 \mathrm{kr} / \mathrm{M}^{2}$. Землевание способствует образованию у газонных растений дополнительных побегов и корней, в результате чего повышается густота травостоя, снижается вероятность заболевания растений грибковыми болезнями. Качество газона оценивается по специальной методике. Результаты оценки заносятся в специальную таблицу (табл. 4). 
Качество травостоя

\begin{tabular}{|l|c|c|c|c|}
\hline \multicolumn{1}{|c|}{ Показатель } & \multicolumn{4}{|c|}{ Категория качества газона } \\
\cline { 2 - 5 } & Высшая & Первая & Вторая & Третья \\
\hline Густота побегов, шт/м² & 10000 & $5000-10000$ & $2500-5000$ & 2500 \\
\hline Цвет травяного покрова & $\begin{array}{l}\text { Темно-зеленый, } \\
\text { однородный }\end{array}$ & $\begin{array}{c}\text { Темно-зеленый, } \\
\text { однородный }\end{array}$ & $\begin{array}{c}\text { Светло-зеленый, } \\
\text { однородный }\end{array}$ & $\begin{array}{c}\text { Светло-зеленый, } \\
\text { пятнистый }\end{array}$ \\
\hline $\begin{array}{l}\text { Проективное } \\
\text { покрытие, } \\
\% \text { площади поля }\end{array}$ & $95-100$ & $85-95$ & $85-50$ & 50 \\
\hline $\begin{array}{l}\text { Сорняки (одуванчик, } \\
\text { просовидные и др.), } \\
\% \text { площади поля }\end{array}$ & 0 & 5 & 10 & 20 \\
\hline $\begin{array}{l}\text { Клевер, } \\
\% \text { площади поля }\end{array}$ & 5 & 10 & 30 & 50 \\
\hline $\begin{array}{l}\text { Наличие кочек в виде } \\
\text { плотных кустов травы, } \\
\% \text { площади поля }\end{array}$ & 0 & До 10 & $25-50$ & $25-50$ \\
\hline $\begin{array}{l}\text { Неровности почвы } \\
\text { площадью до 10 м }{ }^{2}, \\
\% \text { площади поля }\end{array}$ & 0 & До 10 & До 25 & До 25 \\
\hline $\begin{array}{l}\text { Максимальная высота } \\
\text { травостоя, см }\end{array}$ & 10 & 12 & 12 & Более 12 \\
\hline
\end{tabular}

Основным показателем качества является густота травостоя. Высшая категория качества имеет плотность побегов выше 10000 шт/м². Второй важный показатель - цвет и равномерность окраски травостоя, цвет травяного покрова должен соответствовать высшей или первой категории.

\section{Выводы}

1. Учитывая методический подход 15-летнего опыта создания газонов разного типа в деятельности ООО «Сады Семирамиды», возможно выделение этапов в агротехнолологии возделывания газонов, характеризующихся определенными особенностями.

2. Современная агротехнология выращивания многолетних мятликовых трав в газонной культуре юга Красноярского края включает создание плодородного слоя, тщательную обработку почвы, качественный посев травосмесей и уход за посевами.

3. Выбор определенных типов газонов зависит от природных условий территории, их функциональной значимости. Для использования в рекреационных зонах города Красноярска и его пригородов наиболее приемлемы газоны «обыкновенный» и «луговой», для декоративности и усиления фуннции украшения ландшафтноархитектурных ансамблей - «партерный» газон.

4. Подбор травосмесей газонных трав для создания газонов включает травы: мятлик луговой, райграс пастбищный, овсяница луговая, овсяница красная, овсяница овечья, полевица побегоносная. Смешивание этих трав в нужной пропорции позволяет создавать качественные, долголетние газоны.

5. Практическая составляющая исследования заключается в необходимости организации совместно с Министерством сельского хозяйства и торговли края производства семян многолетних мятликовых трав для рекреационных зон города Красноярска и его окрестностей.

\section{Литература}

1. Остапенко П.И. Научно обоснованное кормление молочного скота в условиях Новосибирской области: практ. рекомендации. Новосибирск, 2000. 60 с.

2. Справочник животновода. Красноярск, 1971. 365 C. 
3. Эрвин Брадэ. Кормление крупного рогатого скота // Новое сельское хозяйство. 2014. № 1. C. 69-70.

4. Абрамошвили Г.Г. Спортивные газоны. М.: Советский спорт, 1988. $159 \mathrm{c}$.

5. Дубовицкая О.Ю. Создание устойчивых сельскохозяйственных фитотехнологий для улучшения среды обитания человека // Вестник Российского университета дружбы народов. Сер. «Сельскохозяйственные науки. Агрономия». 2002. № 8. С. 16-23.

6. Князева Т.П. Газоны. М.: Фитон, 2000. 112 с.

7. Мирошниченко Е.Я., Сенаторова Г.И. Ассортимент газонных растений для лесостепной зоны Западной Сибири. Новосибирск: Наука, 1969.

8. Сенаторова Г.И. Морфогенез мятлика лугового и его использование в газонной культуре. Новосибирск: Наука, 1981.

9. Сигалов Б.Я. Долголетние газоны. М.: Наука, $1971.220 \mathrm{c.}$

10. Сокольская О.Б., Иванова И.Е. Закономерная взаимосвязь зеленых насаждений с распространением различных ландшафттов в Саратове // Успехи современного естествознания. 2016. № 2. С. 115-119.

11. Demidenko G.A., Keler V.V., Kriger N.V., Shadrin I.A and S.V. Khizhnyak. Plants species for ecological landscaping in urban territory in Central Siberia/ IOP Conf.Series: Earth and Environmental Science 315 (2019) 052076 doi:10.1088/1755-1315/315/5/052076.

12. Романов В.Н. Полевое кормопроизводство в Красноярском крае / Краснояр. гос. аграр. ун-т. Красноярск, 2014. 63 с.

13. Романов В.Н., Петровский Н.В., Колесникова В.Л. и др. Технологические регламенты на возделывание и заготовку растительных кормов из однолетних и многолетних культур с высоким содержанием обменной энергии и питательных веществ / Краснояр. гос. аграр. ун-т. Красноярск, 2014. 58 c.

\section{Literatura}

1. Ostapenko P.I. Nauchno obosnovannoe kormlenie molochnogo skota $\mathrm{v}$ uslovijah
Novosibirskoj oblasti: prakt. rekomendacii. Novosibirsk, 2000. $60 \mathrm{~s}$.

2. Spravochnik zhivotnovoda. Krasnojarsk, 1971. $365 \mathrm{~s}$.

3. Jervin Bradje. Kormlenie krupnogo rogatogo skota // Novoe sel'skoe hozjajstvo. 2014. № 1. S. 69-70.

4. Abramoshvili G.G. Sportivnye gazony. M.: Sovetskij sport, 1988. $159 \mathrm{~s}$.

5. Dubovickaja O.Ju. Sozdanie ustojchivyh sel'skohozjajstvennyh fitotehnologij dlja uluchshenija sredy obitanija cheloveka // Vestnik Rossijskogo universiteta druzhby narodov. Ser. «Sel'skohozjajstvennye nauki. Agronomija». 2002. № 8. S. 16-23.

6. Knjazeva T.P. Gazony. M.: Fiton, 2000.112 s.

7. Miroshnichenko E.Ja., Senatorova G.I. Assortiment gazonnyh rastenij dlja lesostepnoj zony Zapadnoj Sibiri. Novosibirsk: Nauka, 1969.

8. Senatorova G.I. Morfogenez mjatlika lugovogo i ego ispol'zovanie $v$ gazonnoj kul'ture. Novosibirsk: Nauka, 1981.

9. Sigalov B.Ja. Dolgoletnie gazony. M.: Nauka, 1971. $220 \mathrm{~s}$.

10. Sokol'skaja O.B., Ivanova I.E. Zakonomernaja vzaimosvjaz' zelenyh nasazhdenij s rasprostraneniem razlichnyh landshaftov $v$ Saratove II Uspehi sovremennogo estestvoznanija. 2016. № 2. S. 115-119.

11. Demidenko G.A., Keler V.V., Kriger N.V., Shadrin I.A and S.V. Khizhnyak. Plants species for ecological landscaping in urban territory in Central Siberia / IOP Conf.Series: Earth and Environmental Science 315 (2019) 052076 doi:10.1088/1755-1315/315/5/052076.

12. Romanov V.N. Polevoe kormoproizvodstvo v Krasnojarskom krae / Krasnojar. gos. agrar. un-t. Krasnojarsk, 2014. 63 s.

13. Romanov V.N., Petrovskij N.V., Kolesnikova V.L. i dr. Tehnologicheskie reglamenty na vozdelyvanie i zagotovku rastitel'nyh kormov iz odnoletnih i mnogoletnih kul'tur s vysokim soderzhaniem obmennoj jenergii i pitatel'nyh veshhestv / Krasnojar. gos. agrar. un-t. Krasnojarsk, 2014. $58 \mathrm{~s}$. 